\title{
Vision impairment predicts 5 year mortality
}

\begin{abstract}
Aim-To describe predictors of mortality in the 5 year follow up of the Melbourne Visual Impairment Project (VIP) cohort. Methods-The Melbourne VIP was a population based study of the distribution and determinants of age related eye disease in a cluster random sample of Melbourne residents aged 40 years and older. Baseline examinations were conducted between 1992 and 1994. In 1997, 5 year follow up examinations of the original cohort commenced. Causes of death were obtained from the National Death Index for all reported deaths.

Results-Of the original 3271 participants, $231(7.1 \%)$ were reported to have died in the intervening 5 years. Of the remaining 3040 participants eligible to return for follow up examinations, 2594 (85\% of eligible) did participate, $51(2 \%)$ had moved interstate or overseas, $83(3 \%)$ could not be traced, and $312(10 \%)$ refused to participate. Best corrected visual acuity $<6 / 12(O R=2.34)$ was associated with a significantly increased risk of mortality, as were increasing age $(O R=1.09)$, male sex $(O R=1.62)$, increased duration of cigarette smoking $(\mathrm{OR}=2.06$ for smoking $>30$ years), increased duration of hypertension $(O R=1.51$ for duration $>10$ years), and arthritis $(\mathrm{OR}=1.42)$.

Conclusions-Even mild visual impairment increases the risk of death more than twofold. Further research is needed to determine why decreased visual acuity is associated with increased risk of mortality.

(Br f Ophthalmol 2001;85:322-326)
\end{abstract}

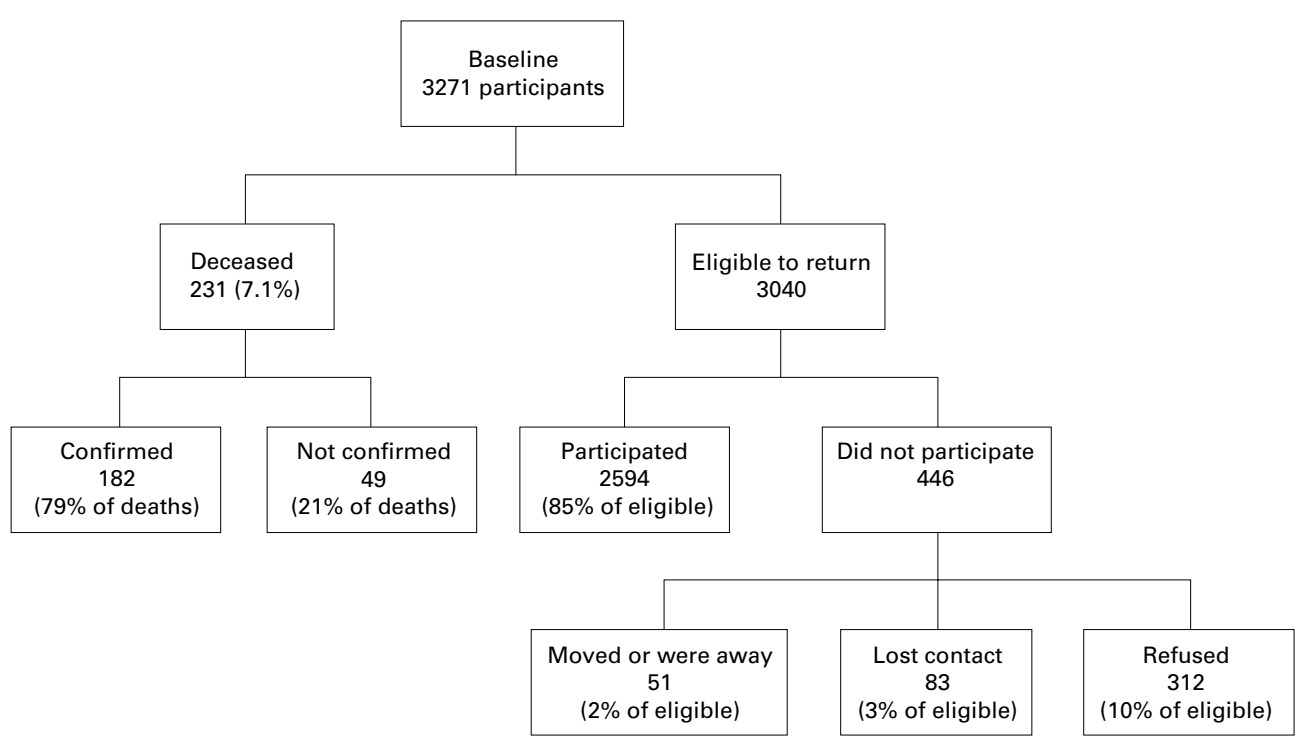

\section{Methods}

Details of the methodology employed for the baseline Melbourne VIP examinations have been published previously. ${ }^{16}$ Briefly, cluster random sampling was employed to identify nine pairs of census collector districts in the Melbourne statistical division from which to recruit eligible residents. Eligible adults were defined as people aged 40 years and older who had been resident in their homes for at least 6

Centre for Eye Research Australia, University of Melbourne, Royal Victorian Eye and Ear Hospital, Melbourne, Australia C A McCarty M B Nanjan H R Taylor

Correspondence to: Cathy McCarty, Centre for Eye Research Australia, University of Melbourne, Royal Victorian Eye and Ear Hospital, 32 Gisborne Street, East Melbourne, Vic 3002, Australia

cathy@cera.unimelb.edu.au

Accepted for publication 3 October 2000

A number of studies have shown an association between age related eye conditions and insuggested that cataract, especially nuclear cataract, or cataract surgery may be markers for ageing. In the Beaver Dam Eye Study, people with visual acuity $<6 / 12$ were 1.57 times as

(VIP) was a population based study of the distribution and determinants of age related eye disease in a representative sample of MelBaseline examinations were conducted between 1992 and 1994. We have shown who chose to participate did not differ significantly in any factors that would probably lead to a bias in the estimate of prevalence estiwere commenced to determine the incidence age related eye conditions and risk factors associated with those eye diseases in the elbourne VIP cohort (Fig 1).

predictors of 5 year mortality in our cohort of non-institutionalised adults.

Figure 1 Status of Melbourne Visual Impairment Project participants at 5 year follow up.

\author{
Catherine A McCarty, Mukesh B Nanjan, Hugh R Taylor
}


months. A household census was conducted to identify the eligible residents, collect basic demographic information, and invite the eligible residents to attend the local examination centres. The standardised examinations lasted approximately 90 minutes and included presenting and best corrected visual acuity, reading vision, Humphrey visual fields, intraocular pressure, personal health and health related habits interview, clinical ophthalmic examination, and photography of the lens and fundus. The Wilmer lens grading scheme was used $^{17}$ and cataract was defined as $\geqslant 4 / 16$ cortical opacity, $\geqslant$ nuclear standard 2.0 , or $\geqslant 1 \mathrm{~mm}^{2}$ posterior subcapsular opacity. Glaucoma diagnosis was determined by a consensus of glaucoma experts after review of intraocular pressure, visual fields, and optic discs. ${ }^{18}$ Age related maculopathy was graded from fundus photographs according to the international classification. ${ }^{19}$ The protocol was approved by the human research and ethics committee at the Royal Victorian Eye and Ear Hospital.

Five year follow up examinations commenced in 1997. In 1996, letters were mailed to each of the 3271 people who participated at baseline. These letters contained information about some of the baseline results and alerted them to the fact that 5 year follow up examinations would commence in 1997. Before the commencement of the 5 year follow up examinations at each of the nine test sites, information sessions were held to again inform the participants of the baseline results and to tell them what to expect from the follow up examinations. Again, recruiters contacted each of the original participants to organise convenient appointment times for them, including nights and weekends where necessary. Information about contact people that was provided by the participants at baseline was used to locate people who had moved and to identify those people who had died in the intervening 5 years. If necessary, people were examined in their homes or nursing homes. Interpreters were provided if needed.

Confirmation and causes of death were obtained from the National Death Index, which is maintained by the Australian Institute for Health and Welfare in Canberra. After providing the National Death Index with a list of names and associated age and last known address for the participants that were suspected of having died, researchers at the National Death Index provided a corresponding list of "matched" deaths. They provide a list of causes of death, when known, for individuals who are matched by name, year of birth, and year of death. The matches are assigned a probability of being the same person from the list provided to them.

Interview data were entered directly into a Paradox computer package with consistency checks built in. All other data were entered twice and verified. Statistical analyses were conducted with sas version 6.0. Pearson's $\chi^{2}$ analyses were used to identify univariate predictors of participation and mortality for categorical variables and Mantel-Haenszel $\chi^{2}$ analyses were used for ordinal variables. Multivariate logistic regression analyses were used to identify independent predictors of participation and 5 year mortality. Survival analyses were conducted with the Wilcoxon test for statistical significance of the survival curves. A p value less than 0.05 was considered to be statistically significant.

\section{Results}

At baseline, the VIP cohort was $54 \%$ female and ranged in age from 40 to 98 years, with a mean of 59 years. Of the original 3271 participants, $231(7.1 \%)$ were reported to have died in the intervening 5 years. Forty nine $(21 \%)$ of the deaths could not be confirmed from the National Death Index. Country of birth was significantly related to confirmation of death by the death registry. The percentage of deaths confirmed by the death registry varied by country of birth. It was $86 \%$ for Australian born, $78 \%$ for British born, $74 \%$ for others, $90 \%$ for Italians, and $29 \%$ for Greeks $\left(\chi^{2}, 4 \mathrm{df}\right.$ $=27.2, \mathrm{p}$ value $=0.001)$. The people whose deaths were confirmed by the death registry were not significantly different from those whose deaths were not confirmed by the death registry in terms of age, sex, cortical cataract, nuclear cataract, posterior subcapsular cataract, cataract surgery, age related maculopathy, glaucoma, diabetes, high blood pressure, arthritis, gout, or cardiovascular disease (all $\mathrm{p}>0.10$, data not presented).

Of the remaining 3040 participants eligible to return for follow up examinations, 2594 ( $85 \%$ of eligible) did participate, $51(2 \%)$ had moved interstate or overseas, $83(3 \%)$ could not be traced, and $312(10 \%)$ refused to participate. The time between baseline and follow up examinations ranged between 4 and 7 years (mean 4.5 years, SD 0.64 , median 4 years). The mean age of the participants at follow up was 62.5 years $(10.9,44-101)$ and $1421(55 \%)$ were female.

Factors significantly related to participation at follow up in the 3040 eligible residents were evaluated. Sex was not significantly related to participation, even at the univariate level (data not presented). The vision related outcomes, such as cataract, glaucoma, and decreased visual acuity, were also not significantly related to participation (data not presented). The only factors related to participation that remained in the multivariate model were age, country of birth, and language spoken at home. NonEnglish speakers and people born in Greece, Malta, or Cyprus were significantly less likely to participate. Age only just reached statistical significance in the multivariate model $(p=0.04)$ and all of the 10 year age groups had participation rates of at least $83 \%$.

Predictors of mortality during the 5 years were evaluated in the cohort (Table 1). Non-participants were not included in these analyses. Variables that were not significantly related to mortality included uncorrected refractive error, language spoken at home, PSC cataract, self reported mental conditions, and alcohol intake at baseline (all p>0.05, data not presented). Significant univariate predictors of mortality included age, sex, country of birth, 
Table 1 Predictors of 5 year mortality in the Melbourne VIP cohort

\begin{tabular}{|c|c|c|c|}
\hline Risk factor & 5 Year mortality (\%) & $\chi^{2}, d f, p$ value & Multivariate OR $(95 \% C L)$ \\
\hline Age & & & Age as continuous variable: \\
\hline $40-49, \mathrm{n}=823$ & 1.7 & & \\
\hline $50-59, \mathrm{n}=978$ & 2.8 & & \\
\hline $60-69, n=863$ & 6.6 & & \\
\hline $70-79, \mathrm{n}=445$ & 17.1 & & \\
\hline $80-89, \mathrm{n}=145$ & 33.1 & & \\
\hline $90+, n=17$ & 52.9 & $258.6,5,0.001$ & $1.09(1.07,1.11)$ \\
\hline \multicolumn{4}{|l|}{ Sex } \\
\hline Female, $n=1760$ & 5.7 & & 1.00 \\
\hline Male, $n=1511$ & 8.7 & $11.1,1,0.001$ & $1.62(1.14,2.30)$ \\
\hline \multicolumn{4}{|l|}{ Country of birth } \\
\hline Australia/New Zealand, $\mathrm{n}=1814$ & 7.9 & & 1.00 \\
\hline British Isles, $n=325$ & 8.3 & & $0.92(0.57,1.49)$ \\
\hline Greece/Cyprus/Malta, n=274 & 5.1 & & $0.85(0.45,1.58)$ \\
\hline Italy, $\mathrm{n}=338$ & 8.0 & & $1.03(0.63,1.68)$ \\
\hline Other, $n=519$ & 3.7 & $14.1,4,0.007$ & $0.55(0.32,0.92)$ \\
\hline \multicolumn{4}{|l|}{ Pack years smoking } \\
\hline None, $n=1570$ & 5.5 & & 1.00 \\
\hline$\leqslant 10, \mathrm{n}=539$ & 5.0 & & $0.95(0.57,1.58)$ \\
\hline $11-30, n=562$ & 8.5 & & $1.85(1.21,2.85)$ \\
\hline$\geqslant 30, \mathrm{n}=588$ & 11.7 & $26.5,1,0.001$ & $2.06(1.38,3.08)$ \\
\hline \multicolumn{4}{|l|}{ Duration of high blood pressure } \\
\hline None, $n=2368$ & 5.7 & & 1.00 \\
\hline$\leqslant 5$ years, $\mathrm{n}=301$ & 8.6 & & $0.89(0.55,1.48)$ \\
\hline $6-10$ years, $n=198$ & 7.6 & & $0.73(0.38,1.48)$ \\
\hline$>0$ years, $n=394$ & 14.0 & $33.6,1,0.001$ & $1.51(1.01,2.25)$ \\
\hline \multicolumn{4}{|l|}{ Arthritis } \\
\hline No, $n=2521$ & 5.4 & & \\
\hline Yes, $n=740$ & 12.8 & $48.9,1,0.001$ & $1.42(1.02,1.97)$ \\
\hline \multicolumn{4}{|l|}{ Best corrected visual acuity } \\
\hline$\geqslant 6 / 12, n=3225$ & 6.6 & & \\
\hline$<6 / 12, n=43$ & 37.2 & $60.6,1,0.001$ & $2.34(1.03,5.32)$ \\
\hline \multicolumn{4}{|l|}{ Cortical cataract (excluding surgery) } \\
\hline No, $n=2815$ & 5.5 & & \\
\hline Yes, $n=363$ & 17.4 & $71.4,1,0.001$ & $1.42(0.98,2.06)$ \\
\hline \multicolumn{4}{|c|}{ Nuclear cataract (excluding previous surgery) } \\
\hline No, $n=2888$ & 5.7 & & \\
\hline Yes, $n=289$ & 18.3 & $66.2,1,0.001$ & $0.81(0.53,1.26)$ \\
\hline \multicolumn{4}{|l|}{ Previous cataract surgery } \\
\hline No, $n=3123$ & 6.5 & & \\
\hline Yes, $n=109$ & 23.9 & $47.8,1,0.001$ & $1.52(0.73,3.15)$ \\
\hline \multicolumn{4}{|l|}{ Age related maculopathy } \\
\hline No, $n=2708$ & 5.8 & & \\
\hline Yes, $n=501$ & 13.8 & $41.6,1,0.001$ & $1.36(0.96,1.94)$ \\
\hline \multicolumn{4}{|l|}{ Glaucoma } \\
\hline No, $n=3144$ & 6.8 & & \\
\hline Yes, $n=120$ & 14.2 & $9.5,1,0.002$ & $1.15(0.63,2.11)$ \\
\hline \multicolumn{4}{|l|}{ Uncorrected refractive error } \\
\hline No, $n=2502$ & 6.2 & & \\
\hline Yes, $n=766$ & 9.7 & $10.6,1,0.001$ & $1.34(0.78,2.31)$ \\
\hline \multicolumn{4}{|l|}{ Diabetes } \\
\hline No, $n=3092$ & 6.7 & & \\
\hline Yes, $n=169$ & 13.0 & $9.7,1,0.002$ & $1.34(0.78,2.31)$ \\
\hline \multicolumn{4}{|l|}{ Gout } \\
\hline No, $n=3022$ & 6.7 & & \\
\hline Yes, $n=239$ & 12.1 & $10.2,1,0.001$ & $0.90(0.55,1.47)$ \\
\hline \multicolumn{4}{|l|}{ Cardiovascular disease } \\
\hline No, $n=2903$ & 6.0 & & \\
\hline Yes, $n=345$ & 24.1 & $447.1,1,0.001$ & $1.08(0.72,1.61)$ \\
\hline
\end{tabular}

cigarette smoking, duration of high blood pressure, arthritis, best corrected visual acuity $<6 / 12$, cortical cataract, nuclear cataract, previous cataract surgery, ARM, glaucoma, diabetes, gout, and cardiovascular disease. All of these variables that were statistically significant in the univariate $\chi^{2}$ analyses were entered into a logistic regression model. Increasing age, male sex, increased duration of cigarette smoking, increased duration of high blood pressure, arthritis, and best corrected visual acuity $<6 / 12$ were all associated with a significantly increased risk of mortality in the multivariate model.

Life table analyses were conducted to explore further the relation between decreased visual acuity and mortality (Fig 2). Year of death, which is necessary for these time dependent analyses, was available for $182 / 231$ $(79 \%)$ participants who had died. Although not statistically significant over the time period because of relatively small number of deaths at each time point, the probability of survival at each time point was less for people with best corrected visual acuity $<6 / 12 \quad\left(\chi^{2}=1.59\right.$, $\mathrm{p}=0.21)$. These analyses were adjusted for age and sex, but not for other variables because of the relatively small number of deaths.

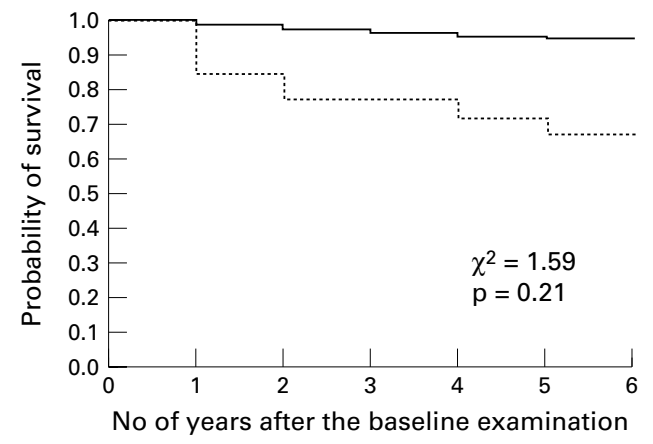

Figure 2 Age and sex adjusted survival curves by level of best corrected visual acuity. Broken line $=<6 / 12$; solid line $=\geqslant 6 / 12$. 
Table 2 Relation of best corrected visual acuity to 5 year mortality in the Melbourne Visual Impairment Project

\begin{tabular}{lrl}
\hline Visual acuity level & Number (\%) who died & OR* $(95 \% C L)$ \\
\hline$\geqslant 6 / 6$ & $107(4.5 \%)$ & Reference \\
$<6 / 6$ to $\geqslant 6 / 9$ & $99(12.3 \%)$ & $1.55(1.09,2.20)$ \\
$<6 / 9$ to $\geqslant 6 / 12$ & $7(30.4 \%)$ & $1.70(0.53,5.48)$ \\
$<6 / 12$ to $\geqslant 6 / 18$ & $10(50.0 \%)$ & $5.48(1.78,16.9)$ \\
$<6 / 18$ to $\geqslant 6 / 60$ & $4(28.6 \%)$ & $1.92(0.49,7.50)$ \\
$<6 / 60$ & $2(22.2 \%)$ & $1.41(0.13,15.34)$ \\
\hline
\end{tabular}

^Adjusted for age, sex, country of birth, smoking, hypertension, arthritis.

Table 3 Causes of death by baseline best corrected visual acuity *

\begin{tabular}{lll}
\hline Cause of death & $\begin{array}{l}\text { Best corrected visual acuity } \\
6 / 12 \text { or better, } n=140\end{array}$ & $\begin{array}{l}\text { Best corrected visual acuity } \\
<6 / 12, n=11\end{array}$ \\
\hline Vascular diseases & $43(30.7 \%)$ & $4(36.4 \%)$ \\
Ischaemic heart disease & $24(17.1 \%)$ & $1(9.1 \%)$ \\
Cancer & $12(8.6 \%)$ & $1(9.1 \%)$ \\
Bronchial conditions & $12(8.6 \%)$ & $0(0 \%)$ \\
Internal organs & $35(25.0 \%)$ & $3(27.3 \%)$ \\
Other (including accident and suicide) & $14(10.0 \%)$ & $2(18.2 \%)$ \\
\hline
\end{tabular}

${ }^{\star} \chi^{2}, 5 \mathrm{df}=2.12, \mathrm{p}=0.83$.

The potential relation between other levels of vision impairment $(<6 / 6,<6 / 9,<6 / 18$, $<6 / 60$ ), and mortality was investigated to determine if a linear trend was evident (Table 2 ). Although all levels of visual acuity $<6 / 6$ were associated with an increased 5 year mortality, only the visual acuity category of $<6 / 6$ to $\geqslant 6 / 9$ was statistically significant.

Causes of death were compared between people with vision $6 / 12$ or better and people with best corrected visual acuity $<6 / 12$ (Table $3)$. Although deaths in the "other" category, including accidents and suicides, were higher in the people with best corrected visual acuity $<6 / 12$, this finding was not statistically significant owing to relatively small number of deaths in the people with decreased visual acuity.

The potential relation between cataract and mortality was investigated further by using a more conservative and a more lenient definition of cortical and nuclear cataract. In none of the four additional multivariate analyses was cataract significantly related to mortality (data not presented).

All of the analyses were repeated after excluding the deaths that could not be confirmed. None of the results changed (data not presented).

\section{Discussion}

We found that decreased visual acuity was associated with increased 5 year mortality. This is consistent with the findings of a study reported in $1966^{2}$ and with the univariate findings of the Beaver Dam Eye Study. ${ }^{9}$ It is plausible that people with vision impairment have increased mortality for a number of reasons. Researchers have shown previously that people with vision impairment are significantly more likely to use healthcare services, ${ }^{20}{ }^{21}$ three times more likely to use regular support services provided by the municipality, ${ }^{22}$ and six times more likely to be unable to go out alone. ${ }^{22}$ Additionally, poorer visual function is associated with increased falls $\mathrm{s}^{23}$ and decreased visual acuity is associated with an increased risk of car accidents. ${ }^{24}$ All of these factors could lead to increased mortality in people with vision impairment. Although the distribution of causes of death was not different between the two groups as a result of a lack of statistical power, there is some evidence that people with decreased visual acuity were more likely to die as a result of other causes, including accidents. Further data and larger numbers would be needed to confirm this potential association.

Several studies have found a positive association between nuclear opacities and mortality, , 9111314 particularly in people with diabetes. ${ }^{4891113}$ Many of these researchers have speculated that lens opacities are a biological marker for ageing. We did not find an association between any cataract type and mortality. Similarly, a recent report from the Physicians' Health Study ${ }^{25}$ revealed no association between a self reported history of cataract and mortality.

A number of studies have also found increased mortality rates among people who have undergone cataract extraction. . $^{3} 691013$ Although we find an increased mortality rate in univariate analyses for people who had undergone cataract surgery, this finding was not statistically significant in our multivariate analyses.

A study reported in the 1960 s showed an association between glaucoma and age specific mortality. ${ }^{1}$ No such association between glaucoma and mortality was seen in the recently conducted Beaver Dam Eye Study. ${ }^{9}$ More recently, high intraocular pressure and glaucoma treatment were found to predict decreased life expectancy in the Framingham Eye Study cohort. ${ }^{12}$ We did not find a relation between glaucoma or intraocular pressure and mortality in multivariate analyses.

In the over 65 year age cohort, there is evidence of a $j$-shaped curve for the relation between alcohol consumption and mortality, with moderate levels of alcohol consumption protective for mortality and larger amounts of alcohol a risk for increased mortality. This j-shaped or u-shaped curve for alcohol consumption and mortality risk has been demonstrated previously. ${ }^{26}$

Smoking is a well known risk factor for mortality and has also been shown to be related to the prevalence and incidence of a number of ocular disorders, including age related macular degeneration $^{27}$ and nuclear cataract. ${ }^{28}$ We found in our study that there was a linear trend between pack years of smoking and mortality.

The strengths of the Melbourne Visual Impairment Project include the sampling strategy and the high response rate which ensure that the study population is representative of Melbourne residents aged 40 years and older. The only factors found to be associated with non-participation by eligible residents in the 5 year follow up examinations were country of birth and language spoken at home. Greeks were significantly less likely to participate, although their response rate is similar to what has been reported for the overall follow up rate in a couple of other large epidemiological studies of eye disease (the Chesapeake Bay Watermen Study and the Baltimore Eye Survey). Not only were the Greeks less likely to participate, but it was also less likely that their 
deaths could be confirmed on the death registry. It is possible that the Greek born participants returned to Greece to die or that their relatives said that they were dead as an excuse for them not to participate. The major limitation of this study is the lack of statistical power, because of the relatively small number of deaths in the cohort, to identify differences in cause specific mortality that might account for the difference in overall mortality rates by visual acuity.

In summary, we have shown that decreased visual acuity is associated with increased mortality in our cohort. Further research is needed to explore why people with decreased vision have a higher mortality rate.

The Melbourne Visual Impairment Project was supported in part by grants from the National Health and Medical Research Council, the Victorian Health Promotion Foundation, the estate of the late Dorothy Edols, the Jack Brockhoff Foundation, the Ansell Ophthalmology Foundation, the Eye Ear Nose and Throat Research Institute, the Appel Family Bequest, and the Hugh Williamson Foundation. Associate professor Cathy McCarty is the recipient of a Wagstaff Research Fellowship in Ophthalmology from the Royal Victorian Eye and Ear Hospital.

This paper was read at the 136th Annual Meeting of the American Ophthalmological Society, Pebble Beach, CA, USA, 21 May 2000

1 Belloc NB. Expectation of life for persons with glaucoma. $\mathcal{F}$ Chron Dis 1963;16:163-71.

2 Rogot E, Goldberg ID, Goldstein H. Survivorship and causes of death among the blind. F Chron Dis 1966;19:17997.

3 Hirsch RP, Schwartz B. Increased mortality among elderly patients undergoing cataract extraction. Arch Ophthalmol 1983;101:1034-7.

4 Podgor MJ, Cassel GH, Kannel WB. Lens changes and survival in a population-based study. $N$ Engl f Med 1985;313: 1438-44.

5 Benson WH, Farber ME, Caplan RJ. Increased mortality rates after cataract surgery. A statistical analysis. Ophthalrates after cataract surger
mology 1988;95:1288-92.

6 Street DA, Javitt JC. National five-year mortality after inpatient cataract. Am f Ophthalmol 1992;113:263-8.

7 Vitale S, West S, Muñoz B, et al. Watermen Study II: mortality and baseline prevalence of nuclear opacity. Inves Ophthalmol Vis Sci 1992;33:S1097.

8 Thompson JR, Sparrow JM, Gibson JM, et al. Cataract and survival in an elderly nondiabetic population. Arch Ophthalmol 1993;111:675-9.

9 Klein R, Klein BEK, Moss SE. Age-related eye disease and survival. The Beaver Dam Eye Study. Arch Ophthalmol 1995;113:333-9.
10 Meddings DR, Marion SA, Barer ML, et al. Mortality rates after cataract extraction. Epidemiology 1999;10:288-93.

11 Hennis A, Wu SY, Nemesure B, et al, Barbados Eye Study Group. Lens opacities and mortality in the Barbados Eye Studies. Invest Ophthalmol Vis Sci 1999;40:S195.

12 Hiller R, Podgor MJ, Sperduto RD, et al. High intraocular pressure and survival: the Framingham Studies. Am f Ophthalmol 1999;128:440-45.

13 Klein R, Klein BEK, Moss SE, et al. Association of ocular disease and mortality in a diabetic population. Arch Ophthalmol 1999;117:1487-95.

14 West SK, Muñoz B, Istre J, et al. Mixed lens opacities and subsequent mortality. Arch Ophthalmol 2000;118:393-7.

15 Livingston PM, Lee SE, McCarty CA, et al. A comparison of participants with non-participants in a population-based epidemiologic study: the Melbourne Visual Impairment Project. Ophthalmic Epidemiol 1997;4:73-81.

16 Livingston PM, Carson CA, Lee SE, et al. Methods for a population-based study of eye disease: the Melbourne Visual Impairment Project. Ophthalmic Epidemiol 1994;1: 139-48.

17 Taylor HR, West SK. A simple system for the clinical grading of lens opacities. Lens Res 1988;5:175-81.

18 Wensor MD, McCarty CA, Stanislavsky YL, et al. The prevalence of glaucoma in the Melbourne Visual Impairment Project. Ophthalmology 1998;105:733-9.

19 The International ARM Epidemiological Study Group. An international classification and grading system for agerelated maculopathy and age-related macular degeneration. Surv Ophthalmol 1995;39:367-74.

20 Chian Y, Javitt J, Metrick S. Health insurance coverage and medical care utilization among working-age Americans with visual impairment. Ophthalmic Epidemiol 1994;1:41-

21 Orr P, Barrón Y, Schein OD, et al. Eye care utilization by older Americans. The SEE Project. Ophthalmology 1999; 106:904-9.

22 Wang JJ, Mitchell P, Smith W, et al. Impact of visual impairment on use of community support services by elderly persons: The Blue Mountains Eye Study. Invest Ophthalmol Vis Sci 1999;40:12-19.

23 Klein BEK, Klein R, Lee KE, et al. Performance-based and self-assessed measures of visual function as related to history of falls, hip fractures, and measured gait time. The Beaver Dam Eye Study. Ophthalmology 1998;105:160-4.

24 Ivers RQ, Mitchell P, Cumming RG. Sensory impairment and driving: the Blue Mountains Eye Study. Am $\mathcal{F}$ Publ Health 1999;89:85-7.

25 Christen WG, Glynn RJ, Ajani UA, et al. Baseline self-reported cataract and subsequent mortality in the Physicians' Health Study I. Ophthalmic Epidemiol 2000;7:11525.

26 Power C, Rodgers B, Hope S. U-shaped relation for alcohol consumption and health in early adulthood and implications for mortality. Lancet 1998;352:877-8.

27 Solberg Y, Rosner M, Belkin M. The association between cigarette smoking and ocular diseases. Surv Ophthalmol 1998;42:535-47.

28 McCarty C, Mukesh BN, Fu CL, et al. The epidemiology of cataract in Australia. Am f Ophthalmol 1999;128:446-65. 